\title{
Analysis of measuring methods of the concentration of methylene blue in the sorption process in fixed-bed column
}

\author{
P. Ostaszewski ${ }^{1}$ O. O. Długosz ${ }^{1}\left[\right.$ [D. Manach ${ }^{1}$
}

Received: 18 April 2020 / Revised: 1 September 2020 / Accepted: 15 January 2021 / Published online: 1 February 2021

(C) The Author(s) 2021

\begin{abstract}
The wastewater from industry is contaminated with dyes, which should be removed in order to prevent environmental damage. This paper presents a method for removing methylene blue from an aqueous solution using a fixed-bed adsorption process onto sawdust. In the article, the method of continuous measurement of methylene blue concentration in the process of sorption on sawdust was used. The results were compared with the results obtained by the standard method of periodic testing of the dye concentration. Continuous measurement of the dye concentration after the sorption process provides the actual nature of the process and the method offers additional information about the process, as opposed to a periodic test in which the concentration of the ingredient gives only averaged results. The kinetics of the methylene blue sorption process at variable initial dye concentrations are presented. The initial concentration of methylene blue had a significant impact on the process breakthrough curve. The increase in concentration (range of $10-90 \mathrm{mg} / \mathrm{dm}^{3}$ ) caused the extension of the penetration zone of the dye mass, thus gradually adsorbing itself on the bed. In the study of kinetics, the Bohart-Adams model was the best fit.
\end{abstract}

Keywords Adsorption $\cdot$ Methylene blue $\cdot$ Fixed-bed $\cdot$ Kinetics $\cdot$ Sawdust

\section{Introduction}

Dye contamination in wastewater derived from many industries including textile, paper, printing, plastics, and cosmetics is difficult and expensive to treat. Dyes in sewage affect photosynthesis by blocking light penetration, even at low concentration (Saini 2017). Methylene blue (MB) is a model dye that is easily visible even at low concentrations (Fu et al. 2015). The compound can be eliminated easily using a variety of methods: ozonation, membrane filtration, electrokinetic coagulation, and adsorption, which have the greatest potential and good efficiency (Ahmad et al. 2015; Sivarajasekar and Baskar 2015). A sorbent that works well in this process is activated carbon, which is also responsible for the high costs involved. There are many researchers that are working on replacing activated carbon with cheaper

Editorial responsibility: Samareh Mirkia.

O. Długosz

odlugosz@chemia.pk.edu.pl

1 Department of Chemical Engineering and Technology, Cracow University of Technology, Warszawska 24, 31-155 Cracow, Poland adsorbents, e.g. waste fruits (Chahm et al. 2018), plant waste (Vyavahare et al. 2019), ashes as eggshell-treated palm oil fuel ash (Hasan et al. 2019), natural and modified zeolites (Bedeenezhad et al. 2019).

The sorption process may be researched by two methods: batch or fixed-bed adsorption (Jain and Gogate 2018). In technology, the continuous method has better prospects due to better performance and an easier optimization process. In dynamic adsorption, it is very important to determine the breakthrough curve, because this gives information that is necessary for the design of the column adsorption system. We can use the breakthrough curves to obtain the practical scale of the column adsorption system (Mohammed et al. 2016). It is possible to find this information in two ways. The first is experimental, which is most likely to be expensive and time-consuming. The second is to develop a mathematical model of the process. Because the processes involved in adsorption between solid and liquid phases are hard to describe, and there are many parameters that can affect them, it is not possible to create just one general mathematical model that describes the breakthrough curve; thus, there have been some models created that are better or worse depending on the specification of process. 
The aim of the study was to investigate the process of removing $\mathrm{MB}$ (a model organic contamination of wastewater) from the water solution by sorption on sawdust. The sorption process was carried out in a continuous system. The efficiency of the sorption method with a mathematical description of the adsorption process dynamics was determined. The purpose of the study was also to describe the sorption process by providing continuous MB concentration measurements.

For both batch and fixed-bed sorption processes, there are difficulties with continuous data collection. In the batch method, in order to measure the sample, the process needs to be stopped. In other words, a few parallel processes are needed to measure one variable, over time. In the column adsorption on fixed-bed method, the effluent is collected in a small vessel for a few minutes and then a sample from the vessel is measured, so the values present an average result from the collecting time (Hu et al. 2015; Kumar et al. 2016). As stated, both of these methods lack continuous measurements, which makes it impossible to describe fully the nature and character of the process. The continuous MB concentration analysis method used in this research allows an average $\mathrm{MB}$ concentration value as a real value to be obtained, even if there is a significant dispersion of the data collected. The middle level of the sorption process (defined as the average concentration value) used in this test method refers to the actual process value.

\section{Materials and methods}

\section{Materials}

In the sorption process, a methylene blue (MB) solution (Avantor Performance Materials Poland S.A. POCH, CAS: $61-73-4,>82 \%$ ) with an initial concentration of $10,30,50$, 70 , and $90 \mathrm{mg} / \mathrm{dm}^{3}$ was used. Wood sawdust was chosen as the adsorbent. The wood sawdust was purchased from a commercial supplier from Poland. The material was of natural origin, as a by-product from the processing of deciduous trees. The average size of the material was approximately $12.5 \times 6.5 \mathrm{~mm}$. All chemicals were used without any further purification.

\section{Methods}

The concentration of MB solution was measured by UV-Vis spectroscopy method (Rayleigh UV-Vis 1800 apparatus) using a flow cuvette (measurements were made every $20 \mathrm{~s}$ ). The concentration of MB was determined by a wavelength of $664 \mathrm{~nm}$, at which a characteristic maximum of MB occurs.

Sawdust was analysed by Fourier transform infrared (FTIR) and scanning electron microscopy with energy-dispersive spectroscopy (SEM-EDS). Based on FTIR, the presence of functional groups of raw material and material after MB sorption was determined. Materials were analysed using an FTIR spectroscope (Nicolet 380), where the spectra were recorded from 3900 to $400 \mathrm{~cm}^{-1}$. Surface morphology and element composition were established using SEM (Vegall-Tescan Company). The analysis of the micro-area was complemented with the use of an EDS detector.

\section{Batch sorption process}

In order to determine the equation coefficients and to investigate the nature of the sorption process, a series of studies on the removal of MB on sawdust in a "batch" contact test were carried out. Three equilibrium models were used to describe the sorption equilibrium parameters: Langmuir, Freundlich, and Temkin. The experiment consisted of mixing $0.2 \mathrm{~g}$ of sawdust with $100 \mathrm{~cm}^{3}$ of MB solution $\left(C_{0}=\right.$ $\left.10-90 \mathrm{mg} / \mathrm{dm}^{3}\right)$. The samples were mixed with a magnetic stirrer at $300 \mathrm{rpm}$ at $20{ }^{\circ} \mathrm{C}$. The sorption time ranged from 5 to $60 \mathrm{~min}$. Next, the solution was separated from the adsorbent by vacuum filtration. The concentration of the dye in the solution was tested by UV-Vis analysis. The sorption capacity of the material was calculated from the dependence:

$q=\frac{V \cdot\left(C_{0}-C_{\mathrm{t}}\right)}{m}$

where $C_{0}$ is the initial MB concentration $\left(\mathrm{mg} / \mathrm{dm}^{3}\right), C_{\mathrm{t}}$ is the retained $\mathrm{MB}$ concentration $\left(\mathrm{mg} / \mathrm{dm}^{3}\right)$ in solution at time $t$, $V$ is the solution volume $\left(\mathrm{dm}^{3}\right)$, and $m$ is the weight of the adsorbent (g).

In the Langmuir model, the substance is adsorbed to form a monolayer. The number of active sites at which processes can take place is steady, and each molecule has a constant enthalpy and sorption activation energy. As a result, the maximum quantity of adsorbed particles is equal to the number of active sites on the surface of the adsorbent, and further adsorption of the component is impossible. The model is presented in the equation:

$q=q_{\max } \frac{k_{\mathrm{L}} \cdot C_{\mathrm{t}}}{1+k_{\mathrm{L}} C_{\mathrm{t}}}$

where $q_{\max }$ is the maximum sorption capacity of the material $(\mathrm{mg} / \mathrm{g}), k_{\mathrm{L}}$ is the Langmuir constant $\left(\mathrm{dm}^{3} / \mathrm{mg}\right)$.

The Freundlich model explains the process of multilayer adsorption. An increase in solution concentration causes continuous adsorption of the molecules. Compared to the Langmuir model, Freundlich's model does not assume inhibition of adsorption once the critical concentration is exceeded, as a result of which no further adsorption would occur. Therefore, the Freundlich equation corresponds to 
processes in a narrow concentration range in which process conditions are physical:

$q=k_{\mathrm{F}} \cdot C_{\mathrm{t}}^{1 / n}$

where $k_{\mathrm{F}}$ and $n$ are constants specific to the system and temperature.

The Temkin model presents a two-parameter equation describing the adsorption process. In the model is assumed an even distribution of the energy of the adsorbent-adsorbate bond, in which with the distance from the surface of the molecules the adsorption energy decreases linearly. The model is presented in the equation:

$q=\frac{R \cdot T}{B} \ln \left(A \cdot C_{\mathrm{t}}\right)$

where $A, B$ are characteristic parameters for the process.

\section{Continuous column system}

The adsorption of MB solution on sawdust was studied using the continuous column method. Sawdust weighing $2.0 \mathrm{~g}$ was packed into a glass column with a height of $102 \mathrm{~mm}$ and a diameter of $11 \mathrm{~mm}$, the height of the bed was $100 \mathrm{~mm}$. Before starting the process, the column was fed with deionised water for $30 \mathrm{~min}$ in an up-flow mode. The flow rate was $0.100 \mathrm{~cm}^{3} / \mathrm{s}$. Figure 1 shows the scheme of the process. The MB (1) was fed into the column (3) from the bottom by piston pump (2). After the sorption process, the MB solution was diluted (4), and absorbance of the dye solution was measured by the UV-Vis spectrophotometer. The solution was diluted using deionised water provided by a pump (5) which was working at different parameters: $0.100,0.500,0.900$, and $1.300 \mathrm{~cm}^{3} / \mathrm{s}$ (depending on the initial MB concentration).

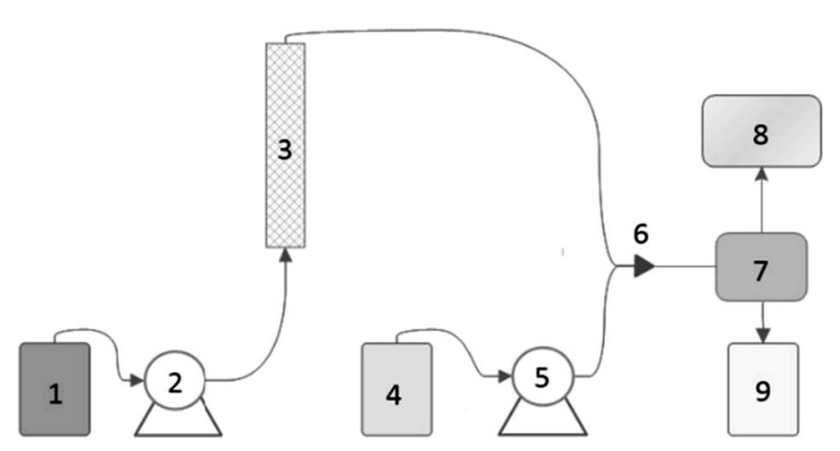

Fig. 1 Scheme of experimental column adsorption system: (1) dye solution, (2) pump, (3) column, (4) deionised water, (5) pomp, (6) tee, (7) UV-Vis spectrophotometer, (8) computer, (9) diluted dye solution

\section{Sorption dynamic}

Two models were tried in order to establish breakthrough curves and other kinetic parameters that describe the process of the adsorption of MB onto sawdust in a fixed-bed column. The MB adsorption process in fixed-bed column for the following models is expressed in terms of $\mathrm{C} / \mathrm{C}_{0}$ as a function of time. The Bohart-Adams Bed Depth Service Time (BDST) model assumes that the adsorption rate is proportional to the concentration of the adsorbing individual as well as to the residual capacity of the adsorbent. This model is used to describe the initial part of the breakthrough curve (Bohart and Adams 1920). The nonlinear form is as follows:

$\frac{C_{\mathrm{t}}}{C_{0}}=\frac{\exp \left(k_{\mathrm{BA}} \cdot C_{0} \bullet t\right)}{\exp \left(k_{\mathrm{BA}} \cdot N_{0} \bullet \frac{H}{v}\right)-1+\exp \left(k_{\mathrm{BA}} \cdot C_{0} \bullet t\right)}$

The Clark model is based on the mass transfer coefficient concept in combination with the Freundlich isotherm (Clark 1987). The nonlinear form is as follows:

$\frac{C_{\mathrm{t}}}{C_{0}}=\left(\frac{1}{1+A_{\mathrm{C}} \cdot \exp (-r \cdot t)}\right)^{\frac{1}{n_{\mathrm{F}}-1}}$

where $C_{\mathrm{t}}\left(\mathrm{mg} / \mathrm{dm}^{3}\right)$ is the effluent concentration of MB at time (min), $C_{0}\left(\mathrm{mg} / \mathrm{dm}^{3}\right)$ is the initial MB concentration, $k_{\mathrm{BA}}\left[\mathrm{dm}^{3} /(\operatorname{min~mg})\right]$ is the Bohart-Adams kinetic constant, $N_{0}\left(\mathrm{mg} / \mathrm{dm}^{3}\right)$ is the maximum volumetric adsorption capacity, $H(\mathrm{~cm})$ is the bed depth in the column, $v(\mathrm{~cm} / \mathrm{min})$ is the flow rate, $A_{\mathrm{C}}$ and $r\left(\mathrm{~min}^{-1}\right)$ are both Clark constants, $n_{\mathrm{F}}$ is the Freundlich constant, and $t$ is the time (min).

\section{Results and discussion}

\section{Discussion}

\section{Characteristics of sawdust}

In the literature, the sawdust was successfully used to remove contaminants, e.g. dyes: Black T Dye (Akhouairi et al. 2019), metal ions including heavy metals, e.g. zinc, copper(II), iron(II), chrome(VI) (Gupta and Babu 2009; Božić et al. 2009), other organic compounds, e.g. phenol (Larous and Meniai 2012). The benefits of the chosen adsorbent are availability, the possibility of using sawdust-based waste material, as well as a high degree of biodegradation, low weight of the material, and extremely low cost.

The SEM microphotographs confirmed a fibrous structure of the material (Fig. 2). The EDS analysis revealed a significant proportion of carbon and oxygen, which, in combination with FTIR analysis, confirms the presence of cellulose, lignin, and hemicellulose. The $3412 \mathrm{~cm}^{-1}$ band proves there 

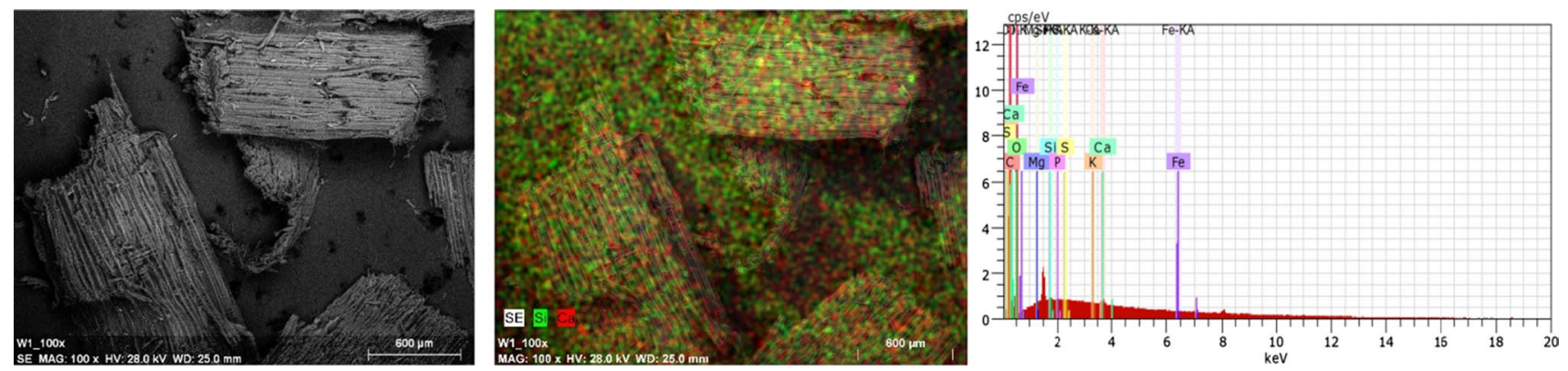

Fig. 2 SEM microphotographs of sawdust $(100 \times)$, with EDS analysis

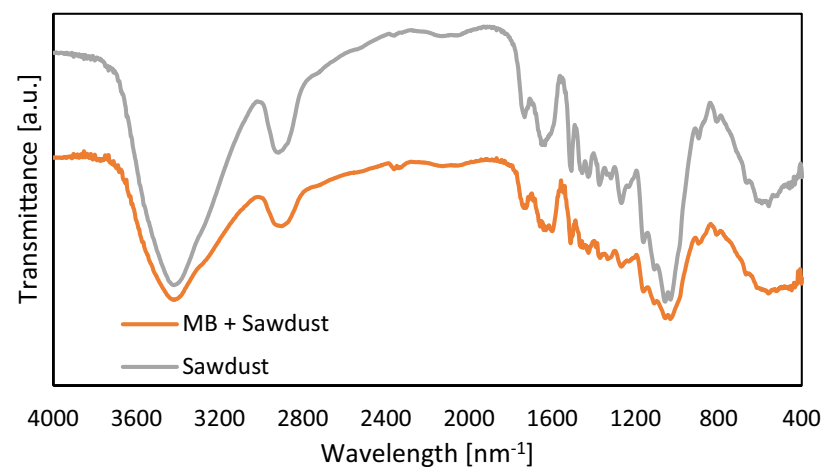

Fig. 3 Image of FTIR analysis for sawdust and sawdust with methylene blue after sorption process

were stretching vibrations of $\mathrm{OH}$ groups, stretching vibrations of alkyl C-H at $2924 \mathrm{~cm}^{-1}$ and of glycoside groups at $897 \mathrm{~cm}^{-1}$, confirming the presence of cellulose. Bands at 1269 and $1059 \mathrm{~cm}^{-1}$ might be in response to stretching $\mathrm{C}-\mathrm{O}$ group vibrations. The band at $1033 \mathrm{~cm}^{-1}$ may result in stretching $\mathrm{C}-\mathrm{O}, \mathrm{C}=\mathrm{O}, \mathrm{C}-\mathrm{C}-\mathrm{O}$ bonds, which are characteristic for cellulose, lignin, and hemicellulose. An aromatic structure can be defined by peaks at 1512 and $1427 \mathrm{~cm}^{-1}$, which are responsible for $\mathrm{C}=\mathrm{C}$ stretching bonds, while the $1464 \mathrm{~cm}^{-1}$ peak comes from bond vibrations of the $\mathrm{C}-\mathrm{H}$ group, and bands under $900 \mathrm{~cm}^{-1}$ result from deformation vibrations.

The figure shows FTIR diagrams that enabled the confirmation of MB sorption on sawdust (Fig. 3). Comparison with the bed before sorption showed an increase in peak power at wavelengths $3412,2924,1059$, and $1033 \mathrm{~cm}^{-1}$. The FTIR spectrum of the sorbent with MB showed that most of the characteristic bonds for the sorbent are occupied by MB because their peaks were extinguished. Two new peaks

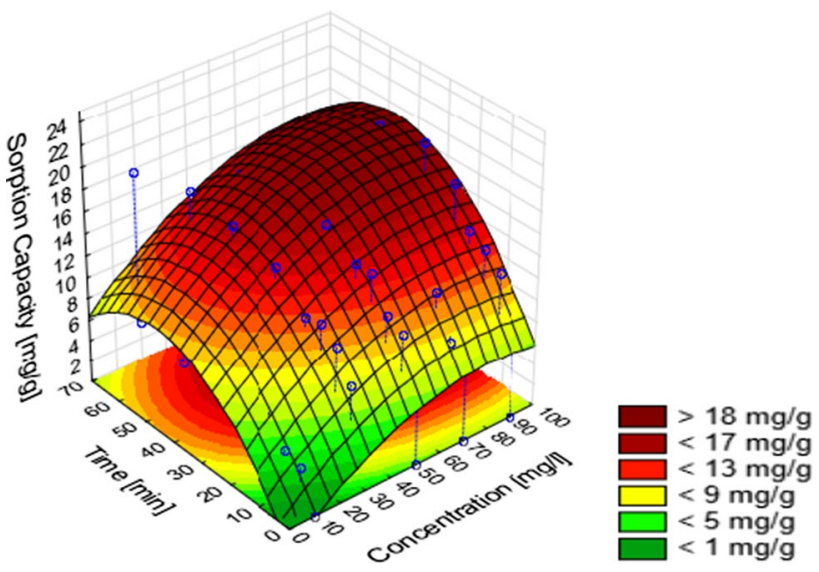

Fig. 4 Sorption capacity of sawdust depending on time and initial $\mathrm{MB}$ concentration

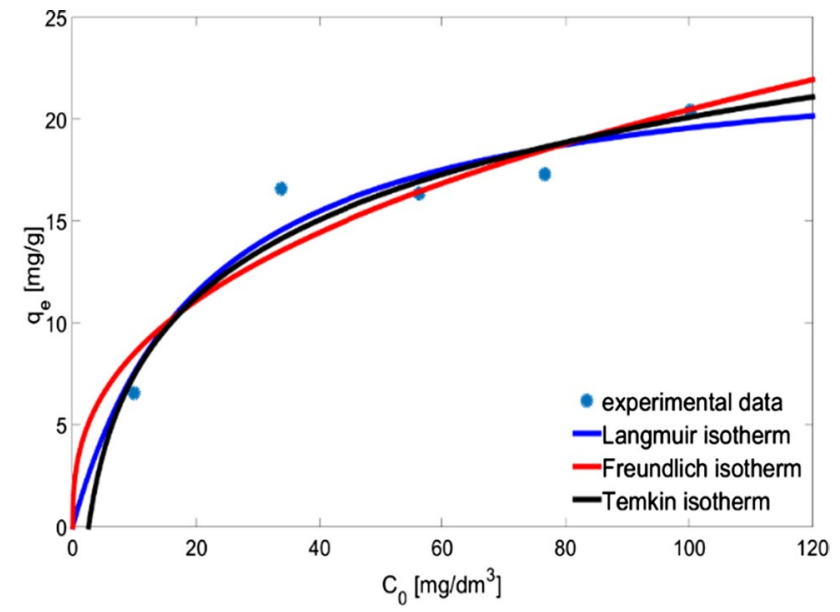

Fig. 5 Sorption isotherms plot of MB onto sawdust 
Table 1 Langmuir, Freundlich, and Temkin isotherm constants and correlation coefficients for MB sorption on sawdust

\begin{tabular}{|c|c|c|}
\hline Isotherm model & Parameter & Value \\
\hline \multirow{3}{*}{$\begin{array}{l}\text { Langmuir } \\
q=\frac{q_{\max } \cdot k_{\mathrm{L}} \cdot C_{\mathrm{t}}}{1+k_{\mathrm{L}} \cdot C_{\mathrm{t}}}\end{array}$} & $q_{\max }(\mathrm{mg} / \mathrm{g})$ & 23.73 \\
\hline & $k_{\mathrm{L}}\left(\mathrm{dm}^{3} / \mathrm{mg}\right)$ & 0.0469 \\
\hline & $R^{2}$ & 0.9252 \\
\hline \multirow{3}{*}{$\begin{array}{l}\text { Freundlich } \\
q=k_{\mathrm{F}} C_{\mathrm{t}}^{1 / n}\end{array}$} & $k_{\mathrm{F}}\left[\mathrm{mg}^{1-(1 / n)} \mathrm{L}^{1 / n} \mathrm{~g}^{-1}\right]$ & 3.542 \\
\hline & $1 / n$ & 0.3808 \\
\hline & $R^{2}$ & 0.8677 \\
\hline \multirow{3}{*}{$\begin{array}{l}\text { Temkin } \\
q=\frac{R T}{B} \ln \left(A C_{t}\right)\end{array}$} & $A\left(\mathrm{dm}^{3} / \mathrm{g}\right)$ & 0.3884 \\
\hline & $B$ & 519.7 \\
\hline & $R^{2}$ & 0.9182 \\
\hline
\end{tabular}

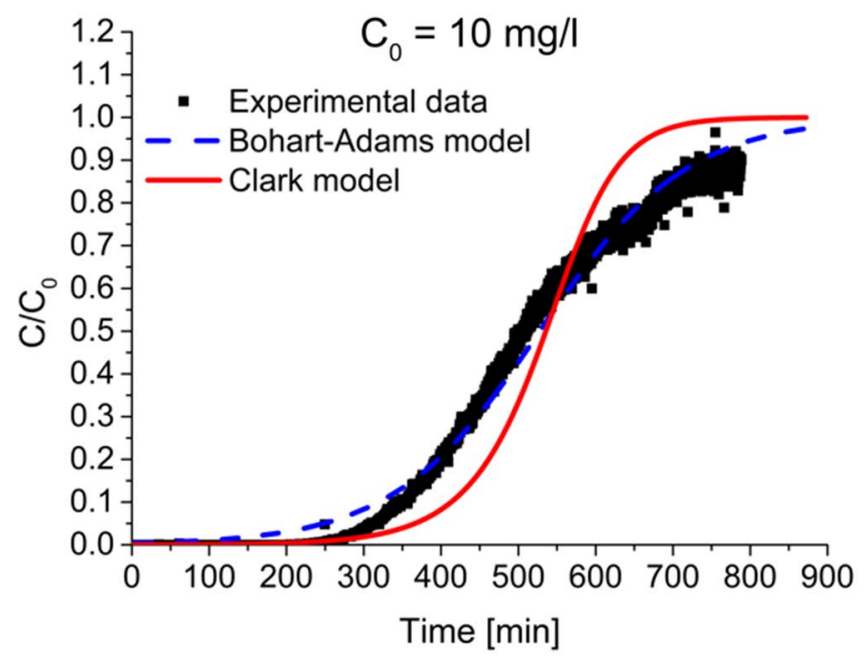

at 1600 and $1658 \mathrm{~cm}^{-1}$ are visible that confirm the sorption of MB onto sawdust (Ovchinnikov et al. 2016).

\section{Sorption dynamic}

Figure 4 presents the simultaneous impact of time and MB initial concentration on the sorption capacity of the sawdust in batch processes.

In order to characterise the adsorption equilibrium of MB on sawdust, it is essential to establish the isotherm models for the equilibrium curve (Fig. 5). Three models have been tested: Langmuir, Freundlich, and Temkin (Table 1). The Langmuir model was characterised by the highest determination coefficient. Similar results of the equilibrium nature of MB sorption were achieved by, among others, Onyeocha et al. (2016) and Chowdhury et al. (2016), who adsorbed MB on sugarcane bark and chaff biomass and by rubber leaf powder, respectively. In the next stage, the determined

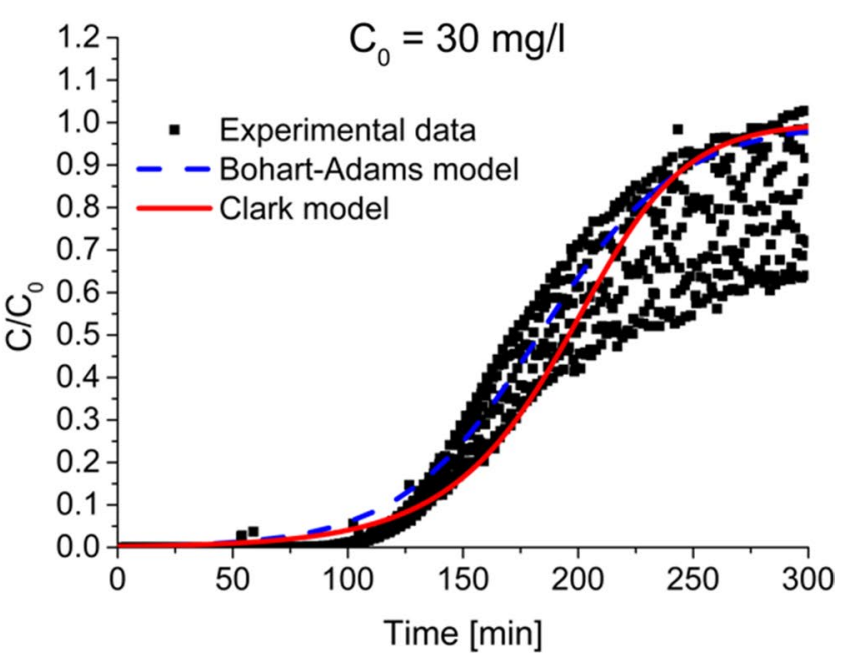

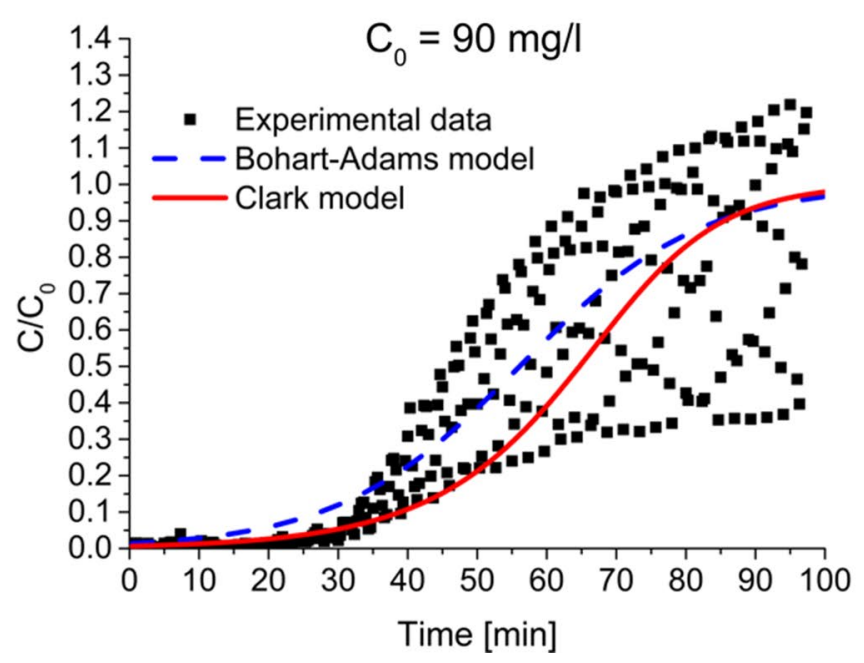

Fig. 6 Graphical presentation of experimental data and fitted models for different initial MB concentrations: 10, 30, and 90 mg/dm ${ }^{3}$ 
coefficients were used in the calculation of breakdown curve models in the fixed-bed adsorption process.

The experimental data obtained in this experiment are not linear. The data are in the shape of cloud of points-a wide range of dispersed values as shown in Fig. 6. Because of this, it is not possible to measure the description of their effective breakthrough curve using a model with $R^{2}$ as it is in data with linear form. To be able to choose the best model and to compare them the percentage of explained variance needs to be used.

The mass transfer coefficient $k_{\mathrm{BA}}$ is the highest at lowest initial concentrations and gradually decreases with an increase in the initial concentration, which may suggest the dominance of external mass transfer actions in the column adsorption process during the initial stages. Auta and Hameed (2014) observed the same correlation between $\mathrm{MB}$ concentration and $k_{\mathrm{BA}}$ which suggests a successful model prediction. The value of Clark constants, $A_{\mathrm{C}}$ constant decreases and $r$ constant increases with the initial MB concentration. The reason for that dependence may be in the specification of the Clark model, because this model is compatible for low values of $C / C_{0}$, and in this specific concentration, the data with low $C / C_{0}$ factor values have a wide dispersion, which may effect in that break of correlation with higher initial MB concentrations. Song et al. (2011) presented similar behaviour of the parameter $A_{\mathrm{C}}$, for changes of initial $\mathrm{MB}$ concentrations as in this paper. Because of the specific method of measurement, the results presenting a lower percentage of explained variance for each of the models analysed (Table 2), which evidently decreased with an increase in the initial MB concentrations. Among the models that were analysed, the best results were given by the Bohart-Adams model. As the initial MB concentration increases and the other parameters remain steady (flow rate and amount of sorbent), the sorption process becomes faster, the data exhibit a wider range of values, and the breakthrough curves are sharper as is shown in Fig. 7.

Higher compatibility of the Adams-Bohart model with experimental data results from the assumptions of the model. The Adams-Bohart model assumes that the rate of

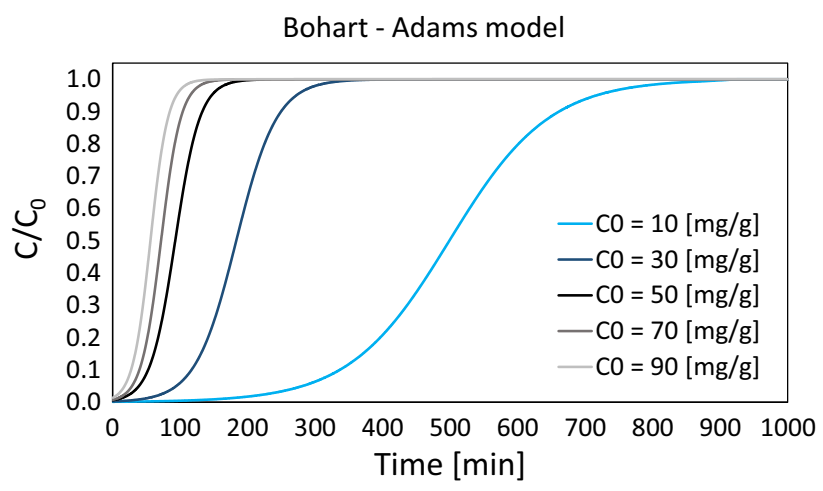

Fig. 7 Bohart-Adams model breakthrough curves for different initial MB concentration (from left to right, 90, 70, 50, 30, $10 \mathrm{mg} / \mathrm{dm}^{3}$ )

adsorption is proportional to the adsorption capacity of the sorbent, and the balance of the process is not momentary, but is an averaged value of the whole process. This model describes the initial shape of the deposit's breakthrough curve particularly well, i.e. when the adsorbent still has most of the free active sites. Over time, the line describing the model is approximately an average result of the measurement points. Clark's model, contrary to the first one, assumes that the shape of the mass permeation zone is constant. In the MB sorption process, the mass transfer zone increases with the length of the column, which can be seen from the increasing distribution of experimental points in Fig. 6. This causes the limited fit of the model to process points.

Figure 7 presents the Bohart-Adams breakthrough curves for MB sorption for different initial MB concentrations. The breakthrough curves are sharper as the initial MB concentrations increase, which was expected as the fixed-bed height is constant. This figure also shows that the differences between the shape of the curves for the low concentrations of 10 and $30 \mathrm{mg} / \mathrm{dm}^{3}$ are much greater than between the high initial MB concentrations 50,70 , and $90 \mathrm{mg} / \mathrm{dm}^{3}$. These breakthrough curves also
Table 2 BDST-Bohart Adams and Clark model parameters obtained using non-linear regression analysis

\begin{tabular}{llllllll}
\hline$C\left(\mathrm{mg} / \mathrm{dm}^{3}\right)$ & \multicolumn{3}{l}{ Bohart-Adams BDST model parameters } & & \multicolumn{3}{l}{ Clark model parameters } \\
\cline { 2 - 3 } & Adjusted $R^{2}$ & $\begin{array}{l}k_{\mathrm{BA}} \\
\left(\mathrm{dm}^{3} \mathrm{mg}^{-1} \mathrm{~min}^{-1}\right)\end{array}$ & $\begin{array}{l}N_{0} \\
\left(\mathrm{mg} \mathrm{dm}{ }^{-3}\right)\end{array}$ & Adjusted $R^{2}$ & $A_{\mathrm{C}}$ & $r\left(\mathrm{~min}^{-1}\right)$ \\
\hline 10 & 0.9649 & 0.001353 & 6.2260 & & 0.9363 & $96.70 \times 10^{4}$ & 0.02436 \\
30 & 0.9141 & 0.001105 & 6.8616 & & 0.8783 & $1.91 \times 10^{4}$ & 0.04654 \\
50 & 0.8507 & 0.001095 & 5.7980 & & 0.8638 & $1.02 \times 10^{4}$ & 0.07912 \\
70 & 0.8262 & 0.000977 & 6.2852 & & 0.8505 & $0.77 \times 10^{4}$ & 0.09105 \\
90 & 0.7582 & 0.000851 & 6.3185 & & 0.7944 & $0.37 \times 10^{4}$ & 0.11579 \\
\hline
\end{tabular}


show that a wide dispersion of values does not have a negative impact on the calculated model. Ponnusami et al. (2008) researched the process of MB sorption onto guava leaf powder using a constant flow rate and initial dye concentration and measured the effect of bed depth for five different values. Measurements were made in the standard way: collecting samples of effluent for some time then analysing them. The breakthrough curves calculated using the Thomas model in this case are sharper with a decrease in the bed depth, which shows similar behaviour to the results obtained in the present work. Hamdaoui researched dynamic sorption of MB by cedar sawdust and crushed brick in a fixed-bed column. He used various models to calculate the breakthrough curves with different flow rate parameters. The samples were collected in the standard way, but in this case the $\mathrm{R}$ value was similar for each of the flow rates. The breakthrough curves predicted by the Clark model show that the experimental data suits the model very well at $C / C_{0}$ ratios of cedar sawdust above 0.07 (Hamdaoui 2006).

\section{Conclusion}

MB can be removed from an aqueous solution using a fixed-bed adsorption process onto sawdust. (The deposit breakthrough for the highest applied concentration of $C_{0, \mathrm{MB}}=90 \mathrm{mg} / \mathrm{dm}^{3}$ was approximately $30 \mathrm{~min}$.) The Langmuir model best characterises the MB sorption balance on sawdust. The highest fit of the model confirms the chemical nature of sorption.

The kinetics of the sorption of MB onto sawdust and breakthrough curves were best described by the Bohart-Adams model. This model assumes that the rate of adsorption is proportional to the adsorption capacity of the sorbent, and the balance of the process is not momentary, but is an averaged value of the whole process. The shapes of the breakthrough curves are sharper with increasing initial MB concentration. The differences in shape between the highest initial MB concentrations were slight, but the differences between the low initial MB concentrations were incomparably greater.

Continuous measurement of the dye concentration after the sorption process provides the actual nature of the process (not only averaged results), and the method offers additional information about the process. In the MB sorption process, the mass transfer zone increases with the length of the column, which can be seen from the increasing distribution of experimental points.
Acknowledgements This research did not receive any specific grant from funding agencies in the public, commercial, or not-for-profit sector.

\section{Compliance with ethical standards}

Conflict of interest The authors report no declarations of interest.

Open Access This article is licensed under a Creative Commons Attribution 4.0 International License, which permits use, sharing, adaptation, distribution and reproduction in any medium or format, as long as you give appropriate credit to the original author(s) and the source, provide a link to the Creative Commons licence, and indicate if changes were made. The images or other third party material in this article are included in the article's Creative Commons licence, unless indicated otherwise in a credit line to the material. If material is not included in the article's Creative Commons licence and your intended use is not permitted by statutory regulation or exceeds the permitted use, you will need to obtain permission directly from the copyright holder. To view a copy of this licence, visit http://creativecommons.org/licenses/by/4.0/.

\section{References}

Ahmad A, Mohd-Setapar SH, Chuong CS, Khatoon A, Wani WA, Kumar R, Rafatullah M (2015) Recent advances in new generation dye removal technologies: novel search for approaches to reprocess wastewater. RSC Adv 5:30801-30818

Akhouairi S, Ouachtak H, Addi AA et al (2019) Natural sawdust as adsorbent for the eriochrome black $\mathrm{T}$ dye removal from aqueous solution. Water Air Soil Pollut 230:1-15

Auta M, Hameed BH (2014) Chitosan-clay composite as highly effective and low-cost adsorbent for batch and fixed-bed adsorption of methylene blue. Chem Eng J 237:352-361

Bedeenezhad A, Azhdarpoor A, Bahrami S, Yousefinejad S (2019) Removal of methylene blue dye from aqueous solutions by natural clinoptilolite and clinoptilolite modified by iron oxide nanoparticles. Molecular Simulation. ISSN: 0892-7022

Bohart GS, Adams EQ (1920) Some aspects of the behavior of the charcoal with respect chlorine. J Am Chem Soc 42:523-544

Božić D, Stanković V, Gorgievski M et al (2009) Adsorption of heavy metal ions by sawdust of deciduous trees. J Hazard Mater 171:684-692

Chahm T, Martins BA, Rodrigues CA (2018) Adsorption of methylene blue and crystal violet on low-cost adsorbent: waste fruits of Rapanea ferruginea (ethanol-treated and $\mathrm{H}_{2} \mathrm{SO}_{4}$-treated). Environ Earth Sci 77:508

Chowdhury S, Yasin M, Uddin MT, Islam MA (2016) Batch and continuous (fixed bed column) adsorption of methylene blue by rubber leaf powder. Int J Integr Sci Technol 2:24-28

Clark RM (1987) Modeling TOC removal by GAC: the general logistic function. J Am Water Works Assoc 79:33-131

Fu J, Chen Z, Wang M, Liu S, Zhang J, Zhang J, Han R, Xu Q (2015) Adsorption of methylene blue by a high-efficiency adsorbent (polydopamine microspheres): kinetics, isotherm, thermodynamics and mechanism analysis. Chem Eng J 259:53-61

Gupta S, Babu BV (2009) Removal of toxic metal Cr(VI) from aqueous solutions using sawdust as adsorbent: equilibrium, kinetics and regeneration studies. Chem Eng J 150:352-365 
Hamdaoui O (2006) Dynamic sorption of methylene blue by cedar sawdust and crushed brick in fixed bed columns. J Hazard Mater B138:293-303

Hasan R, Chong CC, Setiabudi HD, Jusoh R, Jalil AA (2019) Process optimization of methylene blue adsorption onto eggshell-treated palm oil fuel ash. Environ Technol Innov 13:62-73

Hu X, Ding Z, Zimmerman AR, Wang S, Gao B (2015) Batch and column sorption of arsenic onto iron-impregnated biochar synthesized through hydrolysis. Water Res 68:206-216

Jain SN, Gogate PR (2018) Efficient removal of Acid Green 25 dye from wastewater using activated Prunus Dulcis as biosorbent: batch and column studies. J Environ Manag 210:226-238

Kumar D, Pandey LK, Guar JP (2016) Metal sorption by algal biomass: from batch to continuous system. Algal Res 18:95-109

Larous S, Meniai AH (2012) The use of sawdust as by product adsorbent of organic pollutant from wastewater: adsorption of phenol. In: Energy Procedia. Elsevier, pp 905-914

Mohammed N, Grishkewich N, Waeijen HA, Berry RM, Tam KC (2016) Continuous flow adsorption of methylene blue by cellulose nanocrystal-alginate hydrogel beads in fixed bed columns. Carbohydr Polym 136:1194-1202

Onyeocha V, Onwukamike KN, Njoku VO, Chidiebere MA, Oguzie EE (2016) Removal of methylene blue dye pollutant from aqueous solution using sugar cane bark and chaff biomass. Int Lett Chem Phys Astron 69:49-57

Ovchinnikov OV, Evtukhova AV, Kondratenko TS, Smirnov MS, Khokhlov VY, Erina OV (2016) Manifestation of intermolecular interactions in FTIR spectra of methylene blue molecules. Vib Spectrosc 86:181-189

Ponnusami V, Vikram S, Srivastava SN (2008) Guava (Psidium guajava) leaf powder: novel adsorbent for removal of methylene blue from aqueous solutions. J Hazard Mater 152:276-286

Saini RD (2017) Textile organic dyes: polluting effects and elimination methods from textile waste water. Int J Chem Eng Res 9:121-136

Sivarajasekar N, Baskar R (2015) Agriculture waste biomass valorisation for cationic dyes sequestration: a concise review. J Chem Pharm Res 7:737-748

Song J, Zou W, Bian Y, Su F, Han R (2011) Adsorption characteristics of methylene blue by peanut husk in batch and column modes. Desalination 265:119-125

Vyavahare G, Jadhav P, Patil R, Chetan A, Patil D, Gophane A, Yang Y-H, Gurav R (2019) Strategies for crystal violet dye sorption on biochar derived from mango leaves and evaluation of residual dye toxicity. J Clean Prod 207:296-305 